Conolly, M.D., Fellow of the Royal College of Physicians of London, and Physician to the Middlesex Lunatic Asylum at Hanwell. With Plans. London : Churchill. 1847. pp. 188.

Report of the Cumberland Lunatic Asylum, at Dunston Lodge, Gateshead-on-Tyne, for the Year ending January 1, 1847. Edinburgh : Neill. 1847. 8 ro., pp. 24.

The Surgeon's Vade Mecum. By Robert Druitt, F.R.C.S. Fourth Edition. London: Renshaw, 1847. pp. 620. Numerous Wood Engravings.

A History of the Discorery of the Application of Nitrous Oxide Gas, Ether, and other Vapours, to Surgical Operations. By Horace Wells, Hartford, U.S. 1847. pp. 25.

A Case of Large Secondary Prostatic Calculus, removed by Perineal Incision, \&c. By T. Herbert Barker, M.B., (London), \&c. (From the "Transactions of the Provincial Medical and Surgical Association)." Worcester: Deighton. 1847. 8vo.pp. 12.

\section{PROVINCIAL MEDICAL AND SURGICAL} ASSOCIATION.

NOTICE TO MEMBERS.

Gentlemen who have not yet paid their subscriptions for the current year, or who are in arrears, are requested to forward the amount due, either to the Secretary of the District in which they reside, or to the Treasurer or Secretary of the Association.

RUBERT J. N. STREETEN, Secretary.

\section{ERRATA.}

In the No. for April 7 th, at page 187, col. 2, line 2l, after "Infirmary," read 'a few days.'

For April 21st, Meteorological Journal, Mean of the External Thermometer, 9 a.m. at Romsey, for " 25.21 " read ' 35.21.'

METEOROLOGICAL JOURNALS FOR MARCH, 1847.

Kept at Sidmouth, by W.H. Cullen, M.D.; at Honiton, by Mr. Rogers; at Romsey, Hants by Francis Buckell, Esq., Surgeon.

\section{SIDMOUTH.}

Mean of External Thermometer at 9 A.M. 44.17

. . . . . . . . . 9 P.M. 41.86

- . the Maxima, . . . . . 48.92

. . . Minima, . . . . . 36.28

Absolute Mean . . . . . . . . . 41.37

. . . . of ten preceding years. 40.97

Extreme highest on the 23rd . . . . 57.25

. lowest . . 11th . . . . 24.75

. range . . . . . . . 32.50

Greatest daily range . . . . . . .

Least . . . . . . . . . . .

Mean daily range . . . . . . . 11.09

Mean of Barometer at 9 A.M. . . . 30.138

. . . . . 9 P.M. . . . . 29.196

Extreme highest on the 3rd . . . 30.653

. . lowest on the 31st . . . 29.650

. . range . . . . . . . . 1.003

Mean Dew-point, at 9 A. M. . . . . 38.28

.. . . . . 9 P. M. . . . . 36.70

Number of days fine . . . . . . . 12

- . . on which any rain fell .. 13

- . - with snow or hail

- . . . dull without rain . .

Quantity of rain in inches . . . . . 3.06

Prevailing Winds, .............. SE. N.
Honiton.

\begin{tabular}{|c|c|c|c|}
\hline$\ldots \ldots$ & 40.0 & & 42.92 \\
\hline at 8 P.M. & 40.0 & at 9 P.M. & 41.28 \\
\hline ........ & 47.0 & ........ & 50.31 \\
\hline ........ & 35.0 & ....... & 35.06 \\
\hline ........ & 42.0 & ........ & 42.68 \\
\hline on the 22 nd & $5 \dot{7.0}$ & on the 26 th & 61.00 \\
\hline on the 11 th & 21.0 & on the 11th & 18.00 \\
\hline$\cdots$ & 36.0 & ........ & 43.00 \\
\hline$\cdots$ & - & on the 12 th & 25.50 \\
\hline ..... & - & on the 28 th & 4.00 \\
\hline$\cdots \cdots$ & 11. & $\ldots \ldots \ldots$ & 15.55 \\
\hline & 29.51 & $\ldots \ldots \ldots$ & 29.505 \\
\hline 8 P.M. & 29.56 & at 9 P.M. & 29.477 \\
\hline the $3 \mathrm{rd}$ & 30.20 & on the 4 th & 29.010 \\
\hline 9 th \& 20th & 28.90 & on the 28th & 28.930 \\
\hline ..... & 1.30 & ....... & 1.080 \\
\hline
\end{tabular}
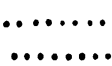

[.......

14

.........

.........

.........

.........

SW. NE. N.

$\cdot$
17
14
-
NE.
umber.

The Uckfield Journals will be given in the next Number.

\title{
TO CORRESPONDENTS:
}

Communications have been receired from Mr. C. L. Prince; the Birmingham Pathological Society ; Mr. W. Allison; Dr. Fife; Dr. Shapter; $\theta$.; Dr. Shearman; the Sheffield Medical Society ; Mr. T. Hunt; and Mr. F. Buckello

It is requested that all letters and communications be sent to Dr. Streeten, Foregate Street, Worcester.

Parcels and books for review, may be addressed to the Editor of the Provincial Medical and Surgical Journal, care of Mr. Churchill, Princes Street, Soho. 